\title{
Effects of chronic stress and high-fat diet on metabolic and nutritional parameters in Wistar rats
}

\author{
Efeitos do estresse crônico e da dieta rica em gordura sobre \\ os parâmetros metabólicos e nutricionais em ratos Wistar
}

Thiago Bruder-Nascimento 1,2, Dijon Henrique Salomé Campos33, Carlos Alves ${ }^{3}$, Samuel Thomaz ${ }^{4}$, Antônio Carlos Cicogna ${ }^{3}$, Sandra Cordellini'

\author{
Department of Pharmacology, \\ Institute of Biosciences, \\ Universidade Estadual Paulista \\ (Unesp), Botucatu, SP, Brazil \\ ${ }^{2}$ Department of Pharmacology, \\ Faculdade de Medicina de \\ Ribeirão Preto, Universidade \\ de São Paulo (FMRP-USP), \\ Ribeirão Preto, SP, Brazil \\ ${ }^{3}$ Department of Medicine Clinical, \\ Faculdade de Medicina de Botucatu, \\ Unesp, Botucatu, SP, Brazil \\ ${ }^{4}$ Department of Morphology, \\ Institute of Biosciences, \\ Unesp, Botucatu, SP, Brazil
}

\begin{abstract}
Objective: The aim of this study was assess the role of chronic stress on the metabolic and nutritional profile of rats exposed to a high-fat diet. Materials and methods: Thirty-day-old male Wistar rats (70-100 g) were distributed into four groups: normal-diet (NC), chronic stress (St), high-fat diet (HD), and chronic stress/high-fat diet (HD/St). Stress consisted at immobilization during 15 weeks, 5 times per week, $1 \mathrm{~h}$ per day; and exposure to the high-fat diet lasted 15 weeks. Nutritional and metabolic parameters were assessed. The level of significance was $5 \%$. Results: The HD group had final body weight, total fat, as well as insulin and leptin increased, and they were insulin resistant. The St and $\mathrm{HD} / \mathrm{St}$ had arterial hypertension and increased levels of corticosterone. Stress blocked the effects of the high-fat diet. Conclusion: Chronic stress prevented the appearance of obesity. Our results help to clarify the mechanisms involved in metabolic and nutritional dysfunction, and contribute to clinical cases linked to stress and high-fat diet. Arq Bras Endocrinol Metab. 2013;57(8):642-9
\end{abstract}

\section{Keywords}

Chronic stress; high-fat diet; calorie intake and food intake

\section{RESUMO}

Objetivo: Avaliar o papel do estresse crônico sobre parâmetros metabólicos e nutricionais de ratos expostos à dieta rica em gordura. Materiais e métodos: Ratos Wistar machos (30 dias de idade/70-100 g) foram distribuídos em quatro grupos: dieta-normal (NC), estresse crônico (St), dieta rica em gordura (HD) e estresse crônico/dieta rica em gordura (HD/St). O estresse consistiu em imobilização durante 15 semanas, 5 vezes por semana $1 \mathrm{~h}$ por dia e a dieta rica em gordura foi oferecida por 15 semanas. Parâmetros nutricionais e metabólicos foram avaliados. 0 nível de significância foi de $5 \%$. Resultadlos: HD tiveram peso corpóreo, gordura total e níveis de insulina e leptina aumentados e foram resistentes à insulina. Os grupos St e HD/St manifestaram hipertensão e níveis séricos de corticosterona elevados. 0 estresse bloqueou os efeitos da dieta. Conclusão: 0 estresse impediu o surgimento dela. Nossos resultados ajudam compreender os mecanismos envolvidos na disfunção metabólica e nutricional e contribuem para casos clínicos de estresse e dietas ricas em gorduras. Arq Bras Endocrinol Metab. 2013;57(8):642-9

Descritores

Estresse crônico; dieta rica em gordura; consumo calórico e metabolismo

\section{INTRODUCTION}

A ccording Selye (1), "stress is the non-specific response of the body to any demand for change". Stress is understood as a complex and multidimensional process $(2)$, in which acute and chronic stress act in different ways. The adaptive response to stress is considered a dynamic process where thoughts, feelings, behaviors, and physiological mechanisms of individual change continuously adjust to the environment $(1,3)$.
The response to stress depends on the intensify, frequency, duration, and kind of stressor agent. The hypothalamus-pituitary-adrenal axis (HPA) and sympathetic autonomic nervous system (SANS) are the main responsible systems in the adaptive response to stress. When these axes are activated, glucocorticoid hormone, cortisol (humans) and corticosterone (rodents), and noradrenaline and adrenaline are released through HPA and SANS axes, respectively. Secondarily, the re- 
nin angiotensin aldosterone system (RAAS) is also activated $(4,5)$.

Stress is linked to several diseases and dysfunctions, such as cardiovascular alterations, immunologic function disorders, asthma, allergy, ulcer, depression, chronic anxiety, insulin resistance, overweight, and obesity (6-12).

Body weight is determined by the interaction between genetics, environment, and psychosocial factors. When the individual is under some factor cited above, some physiologic mediator may regulate calorie intake and energy expenditure. Although genetic disorders are of unquestionable importance, the increased prevalence of obesity may be due to behaviors and environment changes (13). Stress is among the environmental factors that may directly influence to calorie intake.

The literature is controversial about the influence of stress in body weight changes. Rats submitted to chronic stress had their food intake increased, which resulted in greater body weight gain (14). On the other hand, in corticotropin-releasing factor receptor- 2 deficient mice - a genetic mouse model of stress sensitivity - exposed to variable chronic stress, body weight gain was reduced (15). In addition, subordinated mice, those that are not dominant within a group, show greater weight gain compared with dominant rodent, when exposed to a high-fat diet (16).

Therefore, there are few studies showing the link between long chronic stress exposure and high-fat diet about nutritional parameters; our differential features are the 15 weeks of exposition to immobilization stress and our high-fat diet. Given this information, the aim of present study was to assess the role of chronic stress on the metabolic, hormonal, and nutritional profile of rats exposed to a high-fat diet. Our hypothesis is that rats subjected to chronic stress will ingest less food, and consequently, will have their body weight gain decreased.

\section{MATERIAL AND METHODS}

\section{Animal care}

Thirty-day-old male Wistar rats (70-100 g) obtained from the Animal Center of Botucatu Medical School (Botucatu, São Paulo, Brazil) were housed in individual cages. The environment was controlled in terms of light (12 h light/dark cycle starting at $6 \mathrm{am}$ ), clean-air room temperature $\left(23 \pm 3^{\circ} \mathrm{C}\right)$, and relative humidity $(60 \pm 5 \%)$. After 7 days of acclimation, rats were dis- tributed into four groups: normal $\operatorname{diet}(\mathrm{NC}, \mathrm{n}=20)$, chronic stress ( $\mathrm{St}, \mathrm{n}=20)$, high-fat $\operatorname{diet}(\mathrm{HD}, \mathrm{n}=20)$, and chronic stress and high-fat $\operatorname{diet}(\mathrm{HD} / \mathrm{St}, \mathrm{n}=20)$. The animals were weighted weekly. All experiments and procedures were performed in accordance to the Guide for the Care and Use of Laboratory Animals published by the National Research Council, and was approved by the Ethics Committee of the Instituto de Biociências UNESP-Botucatu (protocol $n^{\circ} 95 / 08$-CEEA).

\section{Diet composition}

The NC and St group were fed a standard rat chow containing $4 \%$ fat, $42.7 \%$ carbohydrate, and $22 \%$ protein; whereas the HD and HD/St animals received a high-fat diet containing 20\% fat, $26.4 \%$ carbohydrate, and $20 \%$ protein. Each group was fed the diet for 15 weeks. High-fat diet was designed in our laboratory and contained powdered commercial Agroceres ${ }^{\circledR}$ Animal Chow (Rio Claro, SP, Brazil), industrialized feed, protein supplement, vitamins and minerals. The highfat diet was rich in calories (high-fat diet $=3.65 \mathrm{kcal} / \mathrm{g}$ versus standard diet $=2.95 \mathrm{kcal} / \mathrm{g}$ ) due to the higher fat composition, made with saturated $(20 \%)$ and unsaturated fatty acid $(80 \%)$.

\section{Chronic stress}

After 30 days of age, St and HD/St group were immobilized individually in metal capsules at room temperature $25^{\circ} \mathrm{C}, 1$ hour per day, 5 days a week for 15 weeks (12). During the stress session, ND and HD groups remained in their cages at room temperature $25^{\circ} \mathrm{C}$, without receiving food and water. At the end of the session, the St and HD/St group were placed back in their respective cages.

\section{Systolic blood pressure}

SBP was assessed every three weeks during the 15 weeks. The assessment was carried out by the noninvasive tail-cuff method with a Narco BioSystems ${ }^{\circledR}$ Electro-Sphygmomanometer (International Biomedical, Austin, TX, USA). The average of two pressure readings was recorded for each animal.

\section{Body composition}

After 12-15h fasting, animals were anesthetized with sodium pentobarbital $(50 \mathrm{mg} / \mathrm{kg})$ and euthanized by decapitation. Animals were thoracotomized and total body fat $(\mathrm{BF})$ was measured from the sum of the indi- 
vidual fat pad weights: visceral, epididymal, and retroperitoneal. The adiposity index was calculated by the ratio total body fat to final body weight $\mathrm{x} 100$.

\section{Nutritional profile}

Weekly calorie intake (CI) was calculated by average weekly food consumption $\mathrm{x}$ dietary energetic density. Feed efficiency (FE), the ability to transform calories consumed into body weight (BW), was determined by following the formula: mean body weight gain $(\mathrm{g}) /$ to- $^{-}$ tal calorie intake (kcal).

\section{Hormone assessment}

Corticosterone, insulin, and leptin hormones were also measured. Trunk blood was collected in heparinized tubes, centrifuged at 3,000 g for $15 \mathrm{~min}$ at $4^{\circ} \mathrm{C}$. Corticosterone level was determined by radioimmunoassay using a specific kit (Coat-A-Count Rat Corticosterone - Diagnostic Products Corporation), and leptin and insulin levels were determined ELISA, using commercial kits (Linco Research Inc., USA). In addition, the hypertrophy of adrenal glands also was assessed. The glands were removed, dissected, and weighted.

\section{Metabolic assessment}

Glucose tolerance was also assessed. After a 12-15hour fasting, rats were submitted to a glucose tolerance test (GTT). Blood samples were drawn from the tail at baseline and after administration of glucose $(2 \mathrm{~g} / \mathrm{kg}$, i.p.) (17). Blood samples were collected at $0,15,30$, 60,90 , and 120 minutes. Glucose levels were determined using the ACCU-CHEK GO KIT glucose analyzer (Roche Diagnostic Brazil Ltda., Brazil).

\section{Statistical analysis}

Blood pressure and nutritional, hormonal and metabolic profiles were expressed as means \pm standard deviations. Mean weekly body weight, glucose profile, and blood pressure of the groups were compared by ANOVA for repeated measures and post hoc Bonferronitest. The level of significance was considered to be $5 \%$.

\section{RESULTS}

\section{Nutritional assessment}

There was no statistic difference between ND and St groups in food and calorie intake, and feed efficiency. However, the HD group had decreased food intake. In addition, the same group had the calorie intake and feed efficiency increased. On the other hand, when rats were submitted to both conditions, chronic stress was able to prevent increased calorie intake and feed efficiency increased, which were both observed in the HD group (Figure 1).
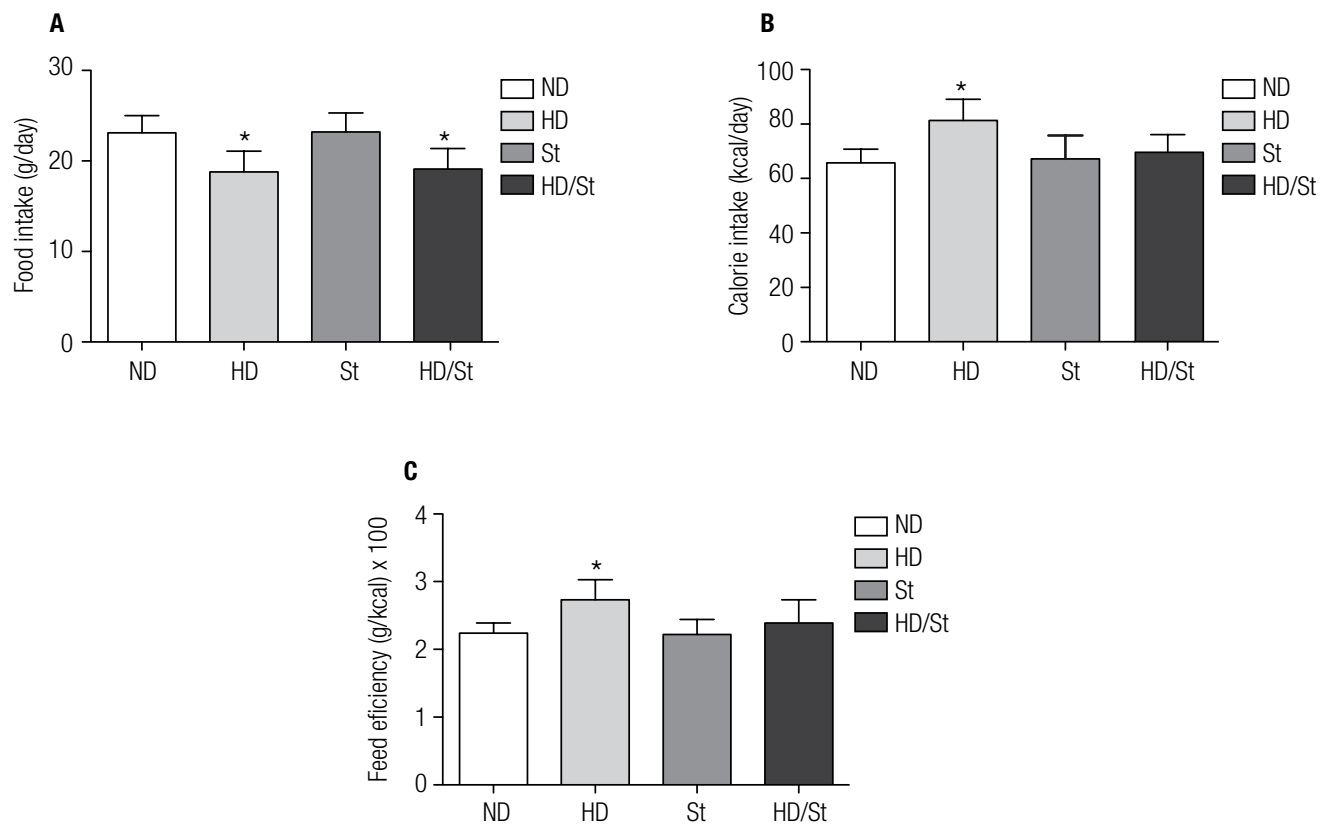

Figure 1. Effects of a high-fat diet (15 weeks of exposure to a special diet) and chronic stress of immobilization ( 15 weeks/5 times per week/1h per day) on food intake $(\mathbf{A})$, calorie intake $(\mathbf{B})$, and feed efficiency $(\mathbf{C})(n=20)$. Data expressed as means \pm standard deviation. ${ }^{*} p<0.05$ vs. respective control. 
Chronic stress did not change body weight, total fat, and adiposity index; however, the high-fat diet induced increase in body weight, fat composition, and adiposity index, and we can suggest that diet was able to induce obesity. On the other hand, chronic stress blocked the high-fat diet effects; it did not enable the increase in body weight gain, as well as the total fat and adiposity index (Figure 2).

\section{Systolic blood pressure, and metabolic and hormone assessment}

Both the groups, St and HD/St, had systolic arterial hypertension when compared with the respectively control. There was no statistic difference between the $\mathrm{ND}$ and HD groups (Figure 3A).

In addition, the $\mathrm{St}$ and $\mathrm{HD} / \mathrm{St}$ groups had increased corticosterone level $v s$. controls, which did not differ between ND and HD. Wet adrenal weight also was increased in animals submitted to chronic stress, these results suggest a HPA axis hyperactivity (Figures $3 \mathrm{~B}$ and $3 \mathrm{C})$.

Leptin level increased in both $\mathrm{HD}$ and $\mathrm{HD} / \mathrm{St}$ groups. However, the HD/St group showed decreased leptin level compared to HD group. In addition, there was no difference in the control group. In relation to insulin level, rats submitted to chronic stress, St and $\mathrm{HD} / \mathrm{St}$ groups, had the leptin level raised. However, HD had a further increase compared with the others groups (Figures 4B and 4C).

Glycemic level did not change among groups from 0 and 15 minutes. However, the HD group was more tolerant to glucose during the whole experiment, whereas, HD/St showed tolerance to glucose $v s$. St from 30 and 60 minutes (Figure 4A).
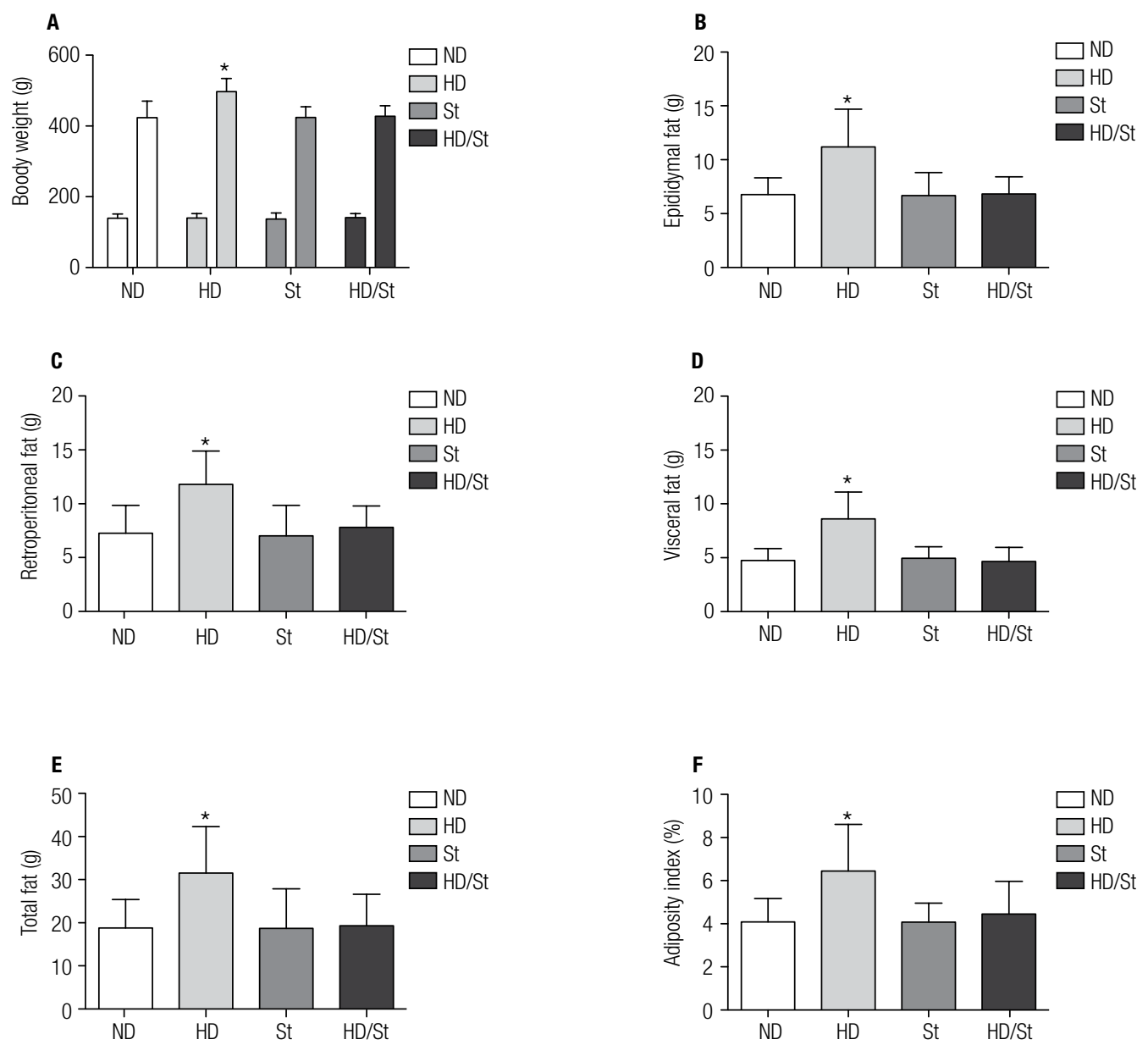

Figure 2. Effects of a high-fat diet (15 weeks of exposure to a special diet) and chronic stress of immobilization (15 weeks/5 times per week/1h per day) on the body weight gain $(\mathbf{A})$, epydidimal fat $(\mathbf{B})$, retroperitoneal fat $(\mathbf{C})$, visceral fat $(\mathbf{D})$, total fat $(\mathbf{E})$, and adiposity index $(\mathbf{F})(n=20)$. Data expressed as means \pm standard deviation. ${ }^{*} p<0.05$ vs. ND. 

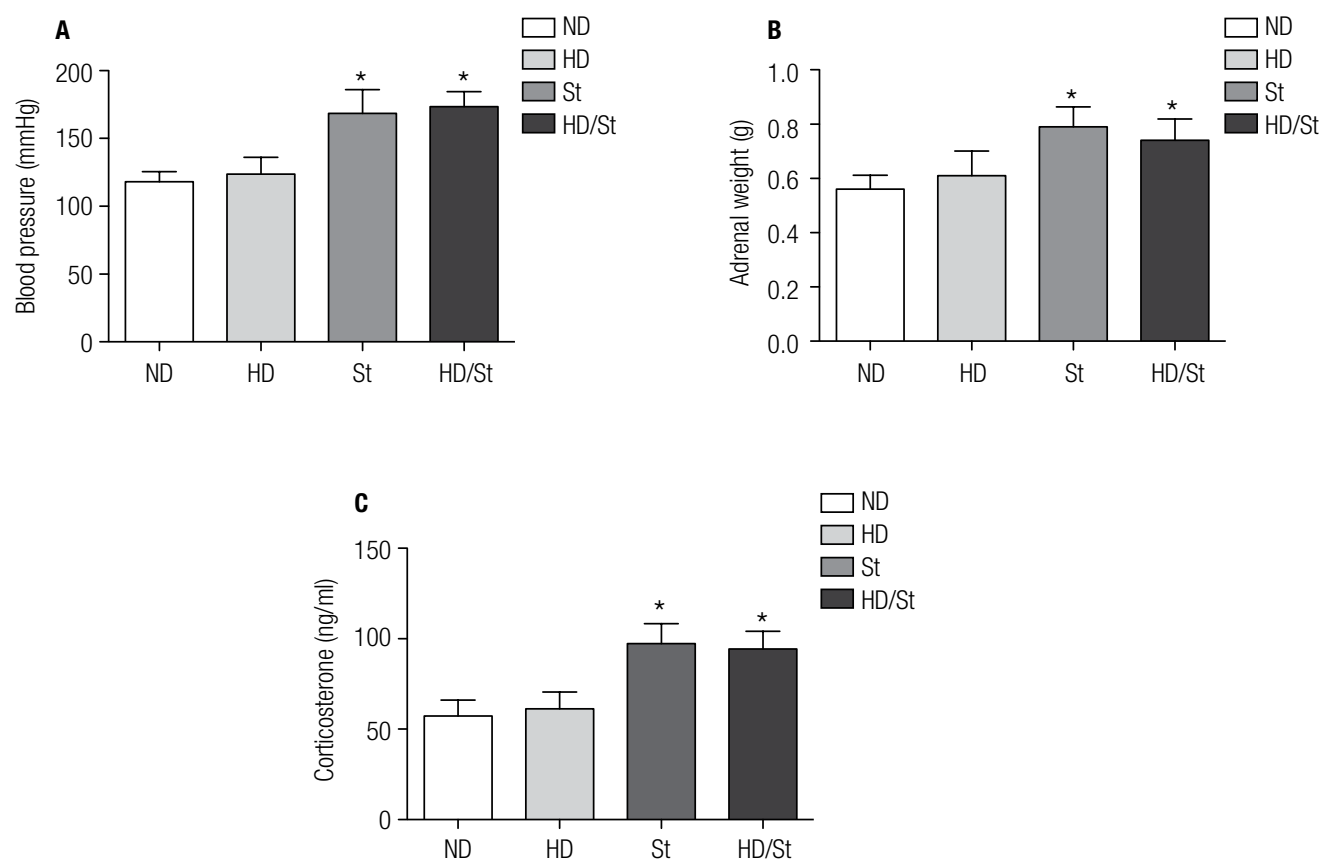

Figure 3. Effects of a high-fat diet ( 15 weeks of exposure to a special diet) and chronic stress of immobilization (15 weeks/5 times per week/1h per day) on final systolic blood pressure $(\mathbf{A})$, wet adrenal weight $(\mathbf{B})$, and corticosterone level $(\mathbf{C})(n=20)$. Data expressed as means \pm standard deviation. * $p<$ 0.05 vs. respective control.
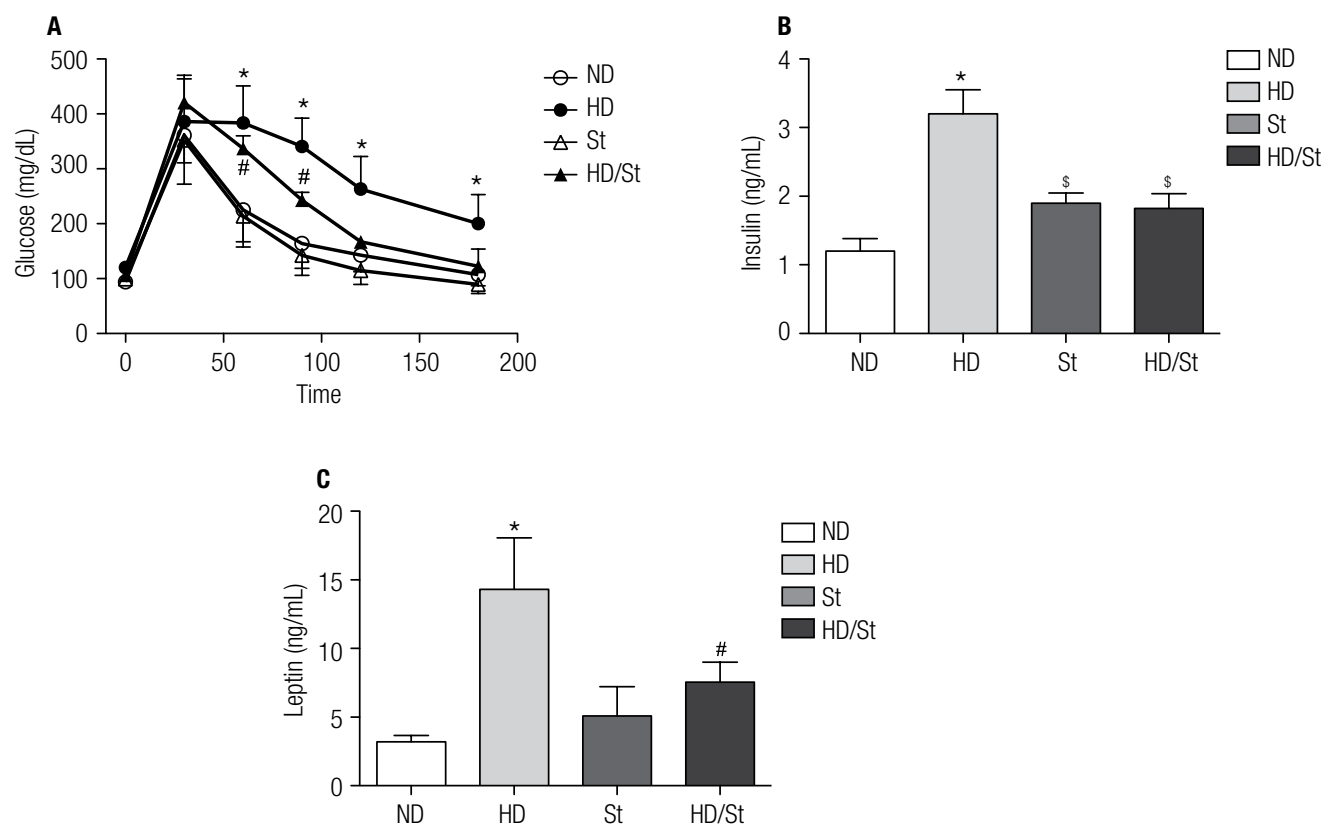

Figure 4. Effects of a high-fat diet (15 weeks of exposure to a special diet) and chronic stress of immobilization (15 weeks/5 times per week/1h per day) on glucose tolerance test $(\mathbf{A})$, insulin level $(\mathbf{B})$, and leptin level $(\mathbf{C})(n=20)$. Data expressed as means \pm standard deviation. ${ }^{\star} p<0.05$ vs. respective control. ${ }^{\#} p<0.05$ vs. St. ${ }^{\$} p<0.05$ vs. ND.

\section{DISCUSSION}

Currently, there are controversies about stress and food intake, and literature shows that chronic stress may lead, in some cases, to increased intake, but mainly to decrease of calorie intake, and consequently, loss of body weight (18). The link between stress, food intake, and weight loss has been used as a reliable marker to assess the severity of the stress model. In humans, stress 
affects feeding of two ways; in one group, about $30 \%$, food intake is decreased, and consequently there is loss of body weight during or after of stressful situation, whereas most people increase food intake during exposure to stress $(19,20)$.

Several studies has used hypercaloric or high-fat diet based on unsaturated fatty acid to analyze obesity $(11,17)$. The present study is in agreement with previous studies $(21,22)$, which show that high-fat diet increases the adiposity index.

One important result of our research was the chronic stress prevented the appearance of obesity in HD/ St; the adiposity index in this group was similar to the ND group. This behavior is in agreement with our initial hypothesis, since we believed that stress was able to attenuate the development of obesity. This phenomenon is related to lower caloric intake in the $\mathrm{HD} / \mathrm{St}$ group; in addition, stress is linked to high levels of catecholamines, which has play central role in lipolysis (10). These findings are different from from data of Chantal and cols. (14), who observed great body weight gain in rats submitted to stress and kept under hypercaloric diet.

Obesity and stress are associated with metabolic dysfunction, e.g., glucose intolerance, insulin resistance, hypertension, hyperglycemia, and increased levels of insulin, leptin, and corticosterone $(10,23)$. In the present study, chronic stress triggered hyperinsulinemia, hypercorticosteronemia, and hypertension, whereas, the HD group showed the same features mentioned above, except for hypertension. The main mechanisms accountable for blood pressure control are SANS hyperactivity, RAAS activity, and oxidative stress, which lead to periphery vasoconstriction and increase sodium reabsorption (24-26). Hypertension, which was observed in rats submitted to chronic stress might be linked as previously mentioned factors, although they were not assessed in the present study. HD group did not show hypertension, this absence of increased blood pressure is in agreement with other previous studies that used similar obesity-inducing methodology $(22,25)$. The stress induced hypertension, which was diet-independent, these results also are in agreement with the literature, that show that stress is related to factors responsible for the increase in blood pressure including SANS and RAAS hyperactivity (10).

Other adaptive response observed in the present study was hypercorticosteronemia in the rodents submitted to chronic stress. Like in hypertension, these alterations are diet-independent; and these results are in agreement with the literature (23). The HPA axis is of the main system responsible for adaptive response to stress. Corticotropin-releasing hormone $(\mathrm{CRH})$ is released by the paraventricular nucleus, which starts the response to stress and plays important role in the hypothalamic adjustment at the HPA axis. CRH stimulates adrenocorticotrophic hormone (ACTH)-releasing by the anterior pituitary. ACTH acts in the fasciculate zone of the adrenal cortex, where it stimulates the releasing of cortisol in humans, or corticosterone in rodents. Cortisol induces the "negative-feedback" in the hypothalamus; it has the responsibility of keeping cortisol concentration within an operational range (4). In addition, chronic stress can promote adrenal hypertrophy (27). Our data corroborate this finding, and we can strongly suggest a HPA axis hyperactivity in rats submitted to chronic stress.

The HD, St and HD/St groups had increased glucose serum levels after anesthesia and decapitation. However, there was no difference in the glucose level in basal conditions in different groups during the glucose tolerance test, as the glucose levels in conscious animals were similar in the four groups. The glucose tolerance test showed that both groups exposed to high-fat diet had increased glycemic level $v s$. rodents exposed to normal diet. This data suggest that stress did not influence glucose behavior after overload. The intolerance to glucose observed in the HD group, considered an intermediated-stage between glucose homeostasis and type 2 diabetes, should be related to the development of insulin resistance in rodents (28).

Insulin biological actions are essential for glucose level control (28). Insulin resistance is defined by decreased sensitivity or loss of its metabolic response. Insulin resistance occurs when insulin flow level are insufficient to adjust this process (29). In this condition, pancreatic- $\beta$ cells secrete larger amounts of insulin, which may be called of hyperinsulinemia, triggering an increase of glucose uptake, it is generated in an attempt for maintain normal glucose levels (30). Our results suggest that the $\mathrm{HD}$ group manifested insulin resistance. Insulin resistance can be generated by alterations in the number of insulin receptors and in insulin signaling (30,31); several researchers have observed that insulin resistance in experimental obesity models may be linked to abnormalities in glucose transporter 4 receptor (GLUT4). This scenario may suggest an abnormality at GLUT4. Although the groups submitted 
to chronic stress did not develop insulin resistance, they had raised insulin level. The literature shows that glucocorticoids and insulin play important roles in energetic balance, and this balance can be impaired in exposure to chronic stress. Glucocorticoids have a diabetogenic function that interferes with insulin action in different levels, such as dysfunction in glucose transport to intracellular space through GLUT4 (32). The increased insulin levels could be explained by SANS hyperactivity, which release noradrenaline and will bind to pancreatic $\beta 2$-adrenergic receptor, producing increased release of insulin (33).

Stress did not change leptin serum levels; however, the hypercaloric diet triggered hyperleptinemia in the HD and HD/St groups, but the HD group had leptin levels further raised vs. HD/St. The hormone leptin is produced by the adipose tissue, and it acts in central nervous system increasing satiety and release of catecholamines (24). The level of leptin is correlated with the amount of body fat; this phenomenon decreases lipogenesis and increases lipolysis (34). Currently, studies have shown that hypercaloric diets blocked leptin action, raising food intake, and leading to increased adiposity $(34,35)$.

In summary, our results are in agreement with our hypothesis, and they suggest that high-fat diet is able to induce obesity, since rats exposed to high-fat diet had increased body weight, total fat, and adiposity index. Furthermore, chronic stress prevented the appearance of obesity. These results help us to understand the dysfunctions observed in humans and rodents. Under stress conditions, humans and rodents can have anorexic symptoms and lose body weight mass. Our results, may help to clarify the mechanisms involved in metabolic dysfunction, and contribute to clinical cases linked to eating disorders. However, more studies are necessary to a better understand of these issues.

Acknowledgements: this study was funded by Fapesp (Fundação de Amparo à Pesquisa do Estado de São Paulo 2009/03771-2).

Disclosure: no potential conflict of interest relevant to this article was reported.

\section{REFERENCES}

1. Selye HA. Syndrome produced by diverse nocuous agents. Nature. 1936;138:32.

2. MCewen BS, Seeman T. Protective and damaging effects of mediators of stress. Elaborating and testing the concepts of allostasis and allostatic load. Ann NY Acad Sci. 1999; 896:30-47.
3. Steadman RG. The assessment of sultriness: part I: a temperaturehumidity index based on human physiology and clothing science. J Appl Meteor. 1979;18:861-84.

4. Huizenga NA, Koper JW, de Lange P, Pols HA, Stolk RP, Grobbee $\mathrm{DE}$, et al. Interperson variability but intraperson stability of baseline plasma cortisol concentrations, and its relation to feedback sensitivity of the hypothalamo-pituitary-adrenal axis to a low dose of dexamethasone in elderly individuals. J Clin Endocrinol Metab. 1998;83(1):47-54.

5. Tsigos C, Chrousos GP. Hypothalamic-pituitary-adrenal axis, neuroendocrine factors and stress. J Psychosom Res. 2002; 53(4):865-71.

6. Rozanski A, Blumenthal JA, Davidson KW, Saab PG, Kubzansky $L$, et al. The epidemiology, pathophysiology, and management of psychosocial risk factors in cardiac practice: the emerging field of behavioral cardiology. Brain Beh Imm 2005;20(2):113-9.

7. Viau V, Meaney MJ. Variations in the hypothalamic-pituitaryadrenal response to stress during the estrous cycle in the rat. Endocrinology. 1991;129(5):2503-11.

8. Hjemdahl P. Stress and the metabolic syndrome. Circulation. 2002;106:2634-6.

9. Vanltallie TB. Stress: a risk factor for serious illness. Metabolism. 2002;1:40-5.

10. Levine TB, Levine AB. Metabolic syndrome and cardiovascular disease. 1.ed. Philadephia: Elsevier, 2006. p. 488.

11. Bruder-Nascimento T, Cordellini S. Vascular adaptive responses to physical exercise and to stress are affected differently by nandrolone administration. Braz J Med Biol Res. 2011;44(4):337-44.

12. Bruder-Nascimento T, Campos DH, Leopoldo AS, Lima-Leopoldo AP, Okoshi K, Cordellini S, et al. Chronic stress improves the myocardial function without altering L-type $\mathrm{Ca}+2$ channel activity in rats. Arq Bras Cardiol. 2012;99(4):907-14.

13. Kopelman PG. Obesity as a medical problem. Nature. 2000; 404:635-43.

14. Chantal M, Barry EL, Ambrose ADM. Stress facilitates body weight gain in genetically predisposed rats on medium-fat diet. Am J Physiol Regul Integr Comp Physiol. 2003;285:R791-9.

15. Teegarden SL, BaleTL. Effects of stress on dietary preference and intake are dependent on access and stress sensitivity. Physiol Behav. 2008;18;93(4-5):713-23.

16. Moles A, Bartolomucci A, Garbugino L, Conti R, Caprioli A, Coccurello $\mathrm{R}$, et al. Psychosocial stress affects energy balance in mice: modulation by social status. Psychoneuroendocrinology. 2006;31(5):623-33.

17. Fatani S, Pickavance LC, Sadler CJ, Harrold JA, Cassidy R, Wilding $J P$, et al. Differential vascular dysfunction in response to diets of differing macronutrient composition: a phenomenological study. Nut Metab. 2007;4:9-15.

18. Levine AS, Morley JE. Stress-induced eating in rats. Am J Physiol. 1981;241(1):R72-6.

19. Stone $A A$, Brownell KD. The stress eating paradox: multiple daily measurements in adult males and females. Psychol Health. 1994;9:425-36.

20. Epel E, Jimenez S, Brownell K, Stroud L, Stoney C, Niaura R. Are stress eaters at risk for the metabolic syndrome? Ann NY Acad Sci. 2004;1032:208-10.

21. Fitzgerald SM, Henegar JR, Brands MW, Henegar LK, Hall JE. Cardiovascular and renal responses to a high-fat diet in Osborne-Mendel rats. Am J Physiol Regul Integr Comp Physiol. 2001;281:H547-52.

22. Carroll JF, Zenebe WJ, Strange TB. Cardiovascular function in a rat model of diet-induced obesity. Hypertension. 2006;48:65-72.

23. Adam TC, Epel ES. Stress, eating and the reward system. Physiol Behav. 2007;91(4):449-58. 
24. Pausova, Z. From big fat cells to high blood pressure: a pathway to obesity-associated hypertension. Curr Opin Nephrol Hypertens. 2006;15:173-8.

25. Relling DP, Esberg LB, Fang CX, Johnson WT, Murphy EJ, Carlson EC, et al. High-fat diet-induced juvenile obesity leads to cardiomyocyte dysfunction and upregulation of Foxo3a transcription factor independent of lipotoxicity and apoptosis. J Hypertens. 2006;24(3):549-61.

26. Boustany-Kari CM, Gong M, Akers WS, Guo Z, Cassis LA. Enhanced vascular contractility and diminished coronary artery flow in rats made hypertensive from diet-induced obesity. Int $\mathrm{J}$ Obes. 2007;31(11):1652-9.

27. Ricart-Jané D, Rodríguez-Sureda V, Benavides A, PeinadoOnsurbe J, López-Tejero MD, Llobera M. Immobilization stress alerts intermediate metabolism and circulating lipoproteins in the rat. Metabolism. 2002;51(7):925-31.

28. Pereira LO, De Franscischi RP, Lancha Jr AH. Obesidade: hábitos nutricionais, sedentarismo e resistência à insulina. Arq Bras Endocrinol Metab. 2003;47(2):111-27.

29. Quon MJ. Limitations of the fasting glucose to insulin ratio as an index of insulin sensitivity. J Clin Endocrinol Metab. $2001 ; 86(10): 4615-7$.
30. Jellinger PS. Metabolic consequence of hyperglycemia and insulin resistance. Clin Cornerstone. 2007;8(7)S30-42.

31. Maegawa H, Kobayashi M, Ishibashi O, Takata $Y$, Shigeta Y. Effect of diet change on insulin action: difference between muscles and adipocytes. Am J Physiol. 1986;251;5(1):E616-23.

32. Field CJ, Ryan EA, Thomson AB, Clandinin MT. Diet fat composition alters membrane phospholipid composition, insulin binding, and glucose metabolism in adipocytes from control and diabetic animals. J Biol Chem. 1990;265(19):11143-50.

33. Frontoni S, Bracaglia D, Baroni A, Pellegrini F, Perna M, Cicconetti E, et al. Early autonomic dysfunction in glucose-tolerant but insulin-resistant offspring of type 2 diabetic patients. Hypertension. 2003;43(6);1223-7.

34. Ainslie DA, Proietto J, Fam BC, Thorburn AW. Short-term, highfat diets lower circulating leptin concentrations in rats. Am J Clin Nutr. 2000;71(2):438-42.

35. Frederich RC, Hamann A, Anderson S, Löllmann B, Lowell BB, Flier JS. Leptin levels reflect body lipid content in mice: evidence for diet-induced resistance to leptin action. Nat Med. 1995;1(12):1311-4. 